\title{
LA CELESTINA COMO HIPOTEXTO GENERADOR DE RUPTURAS NARRATIVAS EN LA LITERATURA HISPÁNICA ACTUAL: EL CASO DEL MANIFIESTO DE CELESTINA (1995) DE MARTA MOSQUERA
}

\author{
Jéromine François \\ Université de Liège \\ Jeromine.Francois@ulg.ac.be
}

\begin{abstract}
RESUMEN: El Manifiesto de Celestina (1995) de la escritora argentina Marta Mosquera representa una verdadera mise en abyme del texto clásico de Rojas. En esta novela fantástica, la intertextualidad con La Celestina genera además una serie de rupturas en la construcción de la novela. En este trabajo, veremos así que el cronotopo, la trama y el narrador se disgregan a medida que se multiplican las citas de la Tragicomedia. Se argumentará luego sobre la reflexión acerca de la literatura y su reescritura a la que da lugar tal proceso de rupturas.
\end{abstract}

PALABRAS CLAVE: La Celestina, Mosquera, intertextualidad, cronotopo, narración

ABSTRACT: The Manifiesto de Celestina (1995) written by the Argentinian author Marta Mosquera embodies a real mise en abyme of Rojas's classic text. The intertextuality with La Celestina creates a series of ruptures within the structure of the novel. In this essay, we will see that the chronotope, the plot and the narrator disperse themselves at the pace of the appearance of more and more quotations from Tragicomedia. We will proceed then to consider their influence on the literary work and the rewriting to which the process of disruptions leads to.

KEYWORDS: La Celestina, Mosquera, intertextuality, chronotope, narrative

\section{Introducción}

La Celestina o Tragicomedia de Calixto y Melibea, obra maestra de la literatura española que nos entregó Rojas a finales del siglo XV, ocupa un lugar singular en la historia literaria por la cantidad impresionante de polémicas que suscitó - y sigue suscitando - entre los críticos. Como bien es sabido y como sintetizó María Rosa Lida de Malkiel (1961) en el insoslayable estudio que dedicó a la obra rojana, tales disensiones atañen por ejemplo a la paternidad del texto, ${ }^{1}$ o a su intención, cristiana y didáctica según algunos (Bataillon, 1961 o Heugas, 1973), subversiva o hasta nihilista para otros (Maestro, 2001). Existe también otra polémica que se refiere a la índole genérica de este relato, que parece combinar rasgos que hoy en día se consideran como teatrales con características actualmente percibidas como novelescas. ${ }^{2}$ Además, y como lo aclara Rojas en una de las piezas preliminares, La Celestina fue refundida por su autor, quien transformó su comedia primigenia en tragicomedia.

Sin embargo, la peculiaridad de esta obra estriba también, y sobre todo, en su índole como libro de rupturas. Este texto se considera en efecto como un eslabón fundamental entre Edad Media y Modernidad, ya que rompe con convenciones literarias medievales (los tópicos

\footnotetext{
${ }^{1}$ Fruto del trabajo de un único autor o de una colaboración entre Rojas y otro escritor cuya identidad se discute todavía en la actualidad.

2 Íñigo Ruiz Arzálluz resume acertadamente estos debates en las páginas 402-417 de la edición de La Celestina publicada por la Real Academia Española en 2011.
} 
corteses) y a partir de allí plantea una superación de las normas sociales y sexuales de la Edad Media, anunciando el Renacimiento.

Fuerza es constatar que si la complejidad de la obra rojana hizo de este modo correr mucha tinta entre los teóricos de la literatura, también provocó una intensa actividad entre los practicantes de la literatura. En efecto, desde su publicación a finales del siglo XV, La Celestina ha dado lugar a muchas continuaciones y adaptaciones que recrean de forma más o menos libre los trágicos amores de Calixto y Melibea facilitados por la alcahueta y hechicera Celestina.

Dentro de esta literatura celestinesca, cada época se empeña en modificar el texto rojano no sólo para que éste se adecue, como parece lógico, a nuevas prácticas lingüísticas y a nuevos contextos históricos y sociales, sino también para que la reescritura refleje los retos estéticos de la literatura que le es coetánea. Así, los hipertextos contemporáneos de la Tragicomedia conforman, a través de su recuperación de la obra clásica, una literatura en búsqueda de nuevos códigos, tanto genéricos como narrativos. En el presente trabajo, examinaré esta tendencia mediante el estudio de una reescritura concreta: el Manifiesto de Celestina. Gracias a las herramientas que me proporcionarán los estudios narratológicos, quisiera demostrar que esta novela corta fantástica, publicada por Marta Mosquera en 1995, utiliza el hipotexto rojano como un mecanismo de rupturas narrativas.

Con tal objetivo, me propongo analizar cómo, en esta obra, los juegos intertextuales permiten generar rupturas narrativas en varios niveles. Así estudiaré las rupturas que atañen a la trama - cuyo encadenamiento lógico de acciones es reemplazado poco a poco por la transcripción estancada del delirio provocado por la lectura del manuscrito celestinesco- - o al cronotopo - que se diluye y se vuelve metafórico a medida que avanza el relato. Luego, veremos que las antedichas rupturas provocan una disgregación de la voz del narrador mediante el paso de una narradora cuya identidad se vuelve cada vez más problemática a una narración asumida por el propio hipotexto - e inician una reflexión acerca de la función de la literatura y del proceso de reescritura.

\section{El Manifiesto de Celestina como mise en abyme de La Celestina}

Escritora argentina que se dedicó a ficciones fantásticas y ensayos sobre teatro y literatura, Marta Mosquera Eastman es autora, entre otras obras, de La cuarta Memoria, El Manuscrito en el espejo o El viraje. En 1960, recibió el Premio "Fondo Nacional de las Artes", cuyo jurado integraba entre otros a Jorge Luis Borges, amigo de la autora a quien dedicó el cuento de El Aleph titulado "La casa de Asterión". Marta Mosquera desarrolló también su labor profesional en el ámbito académico y en el periodístico, ya que combinó una carrera como profesora universitaria - en Argentina, EEUU y Venezuela - con una larga actividad como corresponsal de prensa en París.

El Manifiesto de Celestina parte de esta experiencia periodística: la narradora, cuyo nombre se desconoce, ${ }^{3}$ está investigando por las calles de Caracas con el fin de escribir, para el diario Clarín de Buenos Aires, un artículo sobre el saqueo que acaba de sufrir la ciudad. Durante sus pesquisas callejeras, la narradora entra en "la última casa que estaba de pie" $(9)^{4}$ y que resulta ser la casa de Celestina. En esta morada abandonada tras la muerte de su propietaria, la narradora halla de forma inesperada páginas sueltas de un manuscrito que decide llamar "Manifiesto de Celestina", porque así se llamaba la dueña de la casa. A partir de aquel hallazgo, nace en la mente de la narradora una fascinación cada vez más imperante por el manuscrito desordenado que decide compaginar con el fin de encontrar su coherencia. Esta tarea pronto se

\footnotetext{
${ }^{3}$ Lo cual, junto con la actividad profesional de la misma y la ubicación del relato en Caracas, donde vivía Marta Mosquera cuando escribió el Manifiesto, produce cierta confusión entre narrador-personaje y autor que acerca el texto a los códigos de la autoficción.

${ }^{4}$ Cito siempre de la edición del Manifiesto de Celestina publicada en Caracas por Miguel Ángel García en 1995.
} 
revela sumamente ardua y la narradora decide por tanto apoyarse en la obra de Fernando de Rojas para ordenar el manuscrito, puesto que ambos textos parecen compartir muchos diálogos.

Ya se vislumbra en este argumento un juego especular bastante sofisticado en el que $L a$ Celestina primigenia, la de Rojas, aparece reescrita en un misterioso manuscrito titulado "Manifiesto de Celestina", el cual resulta ser el disparador de otro relato, el Manifiesto de Celestina que el lector tiene en manos. Cabe entonces señalar que, de entrada, las primeras alusiones al hipotexto celestinesco, lejos de ser anecdóticas, condicionan toda la estructura de la obra: la irrupción de La Celestina en el curso del relato cambia el rumbo lineal, acontecimiento tras acontecimiento, de la narración. De ahí en adelante, dicha narración se construirá en efecto como una espiral que pasará continuamente del nivel del "Manifiesto de Celestina", o sea la descripción del manuscrito encontrado por la narradora, al nivel del Manifiesto de Celestina, o sea el relato de la narradora propiamente dicha.

Ahora bien, el paso de un nivel a otro será cada vez más difícil de discernir a medida que avanza la obra. En efecto, su lectura del manuscrito así como su empeño en ordenarlo acaban por provocar el delirio de la narradora, quien se olvida totalmente de su ritmo de vida (trabajar, dormir, comer) porque se entrega cuerpo y alma a una compaginación definida desde el principio como una faena imposible: "infructuosamente organizo el manuscrito de Celestina y marco los textos que sospecho son el «Manifiesto», pero al ordenarlos los desordeno y los vuelvo a escribir" (38). El encadenamiento lógico de acciones es así reemplazado poco a poco por la transcripción estancada de este delirio. La trama acaba por reducirse a la expresión de una obsesión provocada por una lectura y que sólo conduce al fracaso. Reducida a su quintaesencia, la narración de Mosquera no puede sino recordarnos las andanzas quijotescas.

\section{Ruptura del cronotopo y de la voz narrativa}

Si el género fantástico (Andrade et allii, 2010), en literatura, se fundamenta en el enfrentamiento entre un orden racional del mundo y la irrupción de un acontecimiento (extraño, inexplicable, inquietante) que lo niega, entonces fuerza es constatar que, en esta novela corta de Mosquera, es el hipotexto celestinesco el que posibilita este enfrentamiento y el que, por consiguiente, constituye el principal resorte fantástico de la obra. La introducción de citas del texto rojano en la novela corta provoca en efecto una serie de rupturas narrativas que, a su lugar, potenciarán el efecto de ruptura entre realidad e irrealidad, nuclear en el género fantástico. De forma general, el hipotexto genera en el hipertexto una pérdida de referencias, tanto espaciotemporales como ontológicas. Antes de entrar en el análisis propiamente dicho, conviene aclarar que las citas celestinescas omnipresentes en este relato son por lo general o bien citas directas del texto de Rojas, lingüísticamente modernizadas, o bien combinaciones, especies de collage, de distintas citas del texto de Rojas que Mosquera agrupa, añadiéndoles amplificaciones de su cosecha que respetan tanto la temática como la estilística de su modelo tardomedieval.

En relación con las coordenadas espacio-temporales del relato, llama la atención la dilución paulatina del cronotopo. El concepto de cronotopo, cuyos orígenes tienen que ver con un empleo matemático vinculado con la teoría de la relatividad de Einstein, fue utilizado por la crítica literaria a partir de Bajtín, quien definió esta noción en su obra Estética y teoría de la novela. Según él, la conexión entre las coordenadas espaciales y las temporales constituye un cronotopo, el cual funciona a modo de centro organizador de los acontecimientos novelescos (Bajtín, 1989). Al principio de nuestro relato, el cronotopo es la ciudad de Caracas a finales del siglo XX después de un saqueo. ${ }^{5}$ La topografía caraqueña se puede por ejemplo reconocer a

\footnotetext{
${ }^{5}$ Cabe señalar que esta idea de saqueo va a reflejarse rápidamente en la misma narración, donde reina el desorden. El Manifiesto parte de la historia de una devastación en el ámbito material (la ciudad, la casa, las flores) que luego se trasladará al ámbito mental.
} 
través de las calles mencionadas (9). El tiempo empieza a volverse problemático justo después del hallazgo del manuscrito, cuando confiesa la narradora: "No sé realmente el tiempo que pasé en la arepera. Recuerdo que tuve la impresión de que había pasado mucho tiempo. Traté de pensar de qué manera había transcurrido. No logré calcularlo. Busqué un reloj pero en cada reloj la hora era distinta. No supe si habían transcurrido horas, días, años" (11). En este fragmento, la narradora hace hincapié en su percepción subjetiva de la duración. Esta percepción, dificultada primero por una memoria inestable, se proyecta enseguida en el entorno objetivo de la narradora: ni siquiera los relojes la pueden orientar en el tiempo. Como en el caso de la trama, la temporalidad del relato pierde su carácter lineal, progresivo, y se estanca. Para la narradora, y otra vez tras el descubrimiento del manuscrito, pasado, presente y futuro ya no aparecen como etapas temporales consecutivas sino que se desarrollan de forma simultánea: "Los recuerdos más cercanos se confundían con los recuerdos lejanos. En mi memoria se confundían el día de ayer con el día de mañana. Era como si no pudiera reconocer el momento presente" (2).

El concepto de cronotopo, tal y como lo definió Bajtín, implica una interrelación muy importante entre tiempo y espacio. Según el crítico ruso, en una novela el marco cronológico deja efectivamente su impronta en el marco espacial y viceversa. Así no tiene por qué sorprendernos el hecho de que, en el Manifiesto de Celestina, la distorsión sufrida por el marco temporal contamine el entorno espacial:

Hay días que se suceden con tardanza y otros aceleradamente. Constato que algo similar ocurre en relación al espacio que me circunda. Es como si la distancia entre yo y las paredes que me rodean perdieran, insólitamente, su fijeza. Esta impresión se hace más evidente en la casa de Celestina, donde tengo la sensación de estar en un laberinto, de donde no puedo escapar. (18)

Frente a esta distorsión espacial, la narradora intenta apoderarse del espacio repitiendo el mismo recorrido por las calles. No obstante, estas caminatas no hacen sino reforzar este "espacio irreal" (34) en el que la narradora se hunde. Es que las calles por ella conocidas y hasta el hotel donde se aloja parecen recombinarse para conformar un laberinto del que la periodista queda prisionera: "Estoy en el centro del hall. Soy el centro de mi universo, rodeada de las habitaciones cuadradas que se miran unas a otras a través de la galería y se comunican entre ellas como si entraran y salieran hacia un corredor infinito que se aleja y se extiende en todas direcciones, mientras yo corro por él" (43).

Además de volverse más complejo y huidizo, el espacio en el que se mueve la narradora también favorece la progresiva desaparición de las fronteras entre el universo, supuestamente real, en el que vive la periodista y el universo ficticio del manuscrito. El manuscrito de Celestina en efecto llega a contaminar el entorno espacial de la narradora cuando ésta empieza a oír por la ciudad voces citando fragmentos del manuscrito: "la voz de Celestina atraviesa la plaza y retumba contra el caballo de piedra del Libertador" (42). La contaminación entre niveles narrativos ocurre también al revés, cuando el espacio caraqueño se infiltra en el universo celestinesco mediante la inserción de topónimos venezolanos en el relato de las andanzas de un personaje celestinesco: "Entredientes ${ }^{6}$ había llegado donde Celestina sin saber de donde venía, vagando por Barinas, Tucupita, Maracay, Maracaibo" (56). Más adelante, Celestina y su comadre la Claudina ${ }^{7}$ beberán vino en el Zamuro come bailando, un bar en el que la narradora había tomado un café al principio de su narración.

Las antedichas rupturas, que atañen tanto a la trama como a su ubicación espaciotemporal, conllevan por tanto una serie de interrogaciones referidas por una parte a la naturaleza

\footnotetext{
${ }^{6}$ Es éste el nombre dado, en el "Manifiesto de Celestina", al personaje que Rojas llamó Pármeno.

${ }^{7}$ Llamada la Begoña en el texto de Mosquera.
} 
del relato, donde una ficción contamina a otra, y por otra parte a la identidad de una narradora cuya voz se disgrega a medida que narra. Más adelante veremos que estas interrogaciones inician una reflexión más general acerca de la función de la literatura y del proceso de reescritura.

Al entrar en contacto con el manuscrito de Celestina, la narradora se desprende de la realidad cotidiana que la rodea. Este proceso se inicia con la pérdida de memoria que sufre la voz en principio identificable de una periodista: después de encontrar el manuscrito, la narradora se olvida de sus actividades del día anterior. Poco después, la fragmentación y el desorden del manuscrito celestinesco parece reflejarse en la misma memoria de la periodista, una memoria que se hace errática e incompleta, hundiendo a la narradora en una sensación de "inestabilidad" (15) y "perplejidad" (17). Tal desintegración de la memoria de la narradora a su turno va a reflejarse en la propia narración que se repite, retrocede y se pierde en las citas del manuscrito que se hacen cada vez más presentes. La mayor confusión de la narradora se refiere a la frontera entre realidad y ficción: confunde fragmentos del "Manifiesto de Celestina" con voces en la calle y vislumbra trozos del manuscrito en el espacio urbano: "en ese decorado todo parece, misteriosamente habitado por frases y refranes, diálogos y monólogos" (18). A este respecto, es de interés la forma con la que se introducen en la narración las citas del manuscrito celestinesco. Al principio del relato, las citas se identifican claramente como procedentes de la historia ficticia que la narradora está corrigiendo y cuyos pasajes está leyendo. Pero muy rápidamente, las fórmulas que introducen los fragmentos celestinescos se vuelven mucho más ambiguas, ya que la narradora no dice leerlos ni recordarlos sino oírlos. Véanse por ejemplo las introducciones siguientes: "las voces que oigo llegan del fondo del corredor o simplemente es un pedazo del texto que corrijo" (22), "me sorprende el sonido de las voces que llegan desde la mezanina, donde se ensaya una obra de teatro. La obra se parece al manuscrito" (32), o "me despierto porque la voz de Celestina grita" (37).

En estas introducciones, las citas se actualizan en la realidad vivida por la narradora y los personajes parecen salir de su mundo ficticio para invadir el mundo de la narradora. Sin embargo, ésta todavía sigue siendo consciente del vínculo existente entre estas voces y el manuscrito que está leyendo. Esta lucidez mínima, no obstante, acaba por desaparecer cuando la narradora interpreta las citas como diálogos de su vecindario: "Siempre están cerca de mí las voces de los vecinos que apagaron la luz" (79).

Esta asimilación de su entorno al universo celestinesco desemboca luego en las interrogaciones existencialistas de la narradora, ya que al cuestionar la índole del manuscrito acaba por cuestionar su propio ser: “¿Estas páginas acaso son versiones de mi existencia, o acaso el manuscrito me condiciona o yo lo condiciono? [...] ¿Quién soy? ¿Dónde vivo? ¿Qué hago?" (39). La narradora parece diluirse en su lectura del manuscrito, hasta confundirse a sí misma con uno de los personajes de dicho manuscrito: "¿Celestina o yo?, sueña con Melibea" (50), "hasta siento el temor de que mi voz sea la voz de Celestina" (67). La narradora finalmente se considera parte de la trama, ya sea como personaje del manuscrito, ya sea como motivo o tema de la celestinesca: "soy Celestina, Calixto, Melibea, Sempronio, Meandro, soy el amor y los amores entre virgos, mentiras, robos, crímenes, blasfemias, congojas, rumores y refranes" (22). Tal traspaso de la frontera entre el nivel diegético de la narradora y la diégesis, o sea el mundo narrado por el narrador (aquí el mundo del manuscrito) corresponde a lo que Gérard Genette (2004) llama la metalepsis. Fludernik (2005: 77) define la metalepsis ontológica como "una técnica narrativa en la cual el autor parece desplazarse literalmente desde el mundo real hacia el mundo del libro, o en la cual un personaje del libro parece desplazarse de la misma manera del nivel diegético que es presentado como la realidad, es decir salir del mundo del libro" (43). En el relato de Mosquera, la metalepsis es doble, ya que Celestina, personaje del manuscrito encontrado por la narradora, cobra vida y adquiere una voz propia en la realidad caraqueña de la narradora a la vez que la narradora pierde sus características individuales para 
convertirse en parte del manuscrito que estaba analizando. La metalepsis llega a su cumbre cuando la narradora empieza a confundir su vida con el manuscrito, cuando empieza a identificarse con una versión literaria de La Celestina: “Soy yo, una caricatura jugando a todos los juegos, soy simplemente un manuscrito oculto en un palinsesto?" (45).

La voz narrativa se disgrega por tanto mediante el paso paulatino de una narradora identificable a una narración llevada a cabo por el propio hipotexto detrás del cual se borra la figura del narrador. Al final del relato, la metalepsis se resuelve de una forma tan repentina que al lector le puede resultar brutal: el relato de las evocaciones temáticas y filosóficas provocadas por la lectura del manuscrito se acaba con una nueva prueba de esta incertidumbre entre ficción y realidad de la que padece la narradora: "no sé si el texto anterior está en el «Manifiesto de Celestina» o si es producto de mi imaginación" (115). Enseguida la periodista reanuda con su vida cotidiana: deja su hotel y sale a la autopista de regreso. Tras haber ingresado en el mundo ficticio de La Celestina, la narradora regresa a su realidad. Me parece por tanto posible considerar esta metalepsis como una estrategia narrativa que representa, para la narradorapersonaje, un trayecto iniciático en el que la periodista, cuya actividad profesional consiste en encontrar unas verdades factuales, pudo acercarse al tipo de verdades proporcionadas por la ficción.

\section{Una iniciación a la literatura y a la reescritura}

En efecto, uno de los principales efectos de la metalepsis - este proceso de ruptura narrativa tan conocido gracias al cuento de Cortázar "Continuidad de los Parques"- es la autoreflexividad: con la fusión de los niveles narrativos y la puesta en escena de la ficción que posibilita la metalepsis, el autor proyecta en su obra su concepción de la literatura y de la escritura. De hecho, el meta-discurso literario aparece en el relato de Mosquera de forma explícita desde la primera lectura del manuscrito por la narradora. Ésta, al intentar ordenar el cuaderno, trata sobre todo de encontrar un sentido coherente en esta páginas sueltas. Por tanto, antes de desaparecer en su objeto de estudio, la figura de la narradora se presenta más bien como una figura de lectora experta. Así, la periodista analiza las primeras citas celestinescas presentes en el relato como si fuera una crítica literaria. Introduce de este modo comentarios sobre la temática, el tono, los personajes e incluso el estilo del manuscrito celestinesco: "En este fragmento se narra la historia de Meandro, después de una escena tradicional de reconocimiento, donde Celestina recuerda con ternura las semanas que pasó "Entredientes" con ella. Este relato podría definirse como una versión de la picaresca criolla o de la simple crónica policial" (24). Mediante este tipo de comentarios, que se multiplican al principio de la novela corta, llegan a confundirse el texto, la narración de la estancia caraqueña de la narradora, y el metatexto, los comentarios del "Manifiesto".

Luego, a medida que la figura de la narradora desaparece en el manuscrito, se pierde este meta-discurso consciente acerca del funcionamiento de la obra literaria. Poco a poco, el ensayo hermenéutico ya no se circunscribe a los análisis puntuales de la narradora sino que se vuelve el trasfondo de todo el relato. Efectivamente, la fusión entre la lectora y su lectura ${ }^{8}$ transforma el conjunto de esta novela corta fantástica en una alabanza de la literatura y en una metáfora de la interpretación literaria según las concepciones de la autora Marta Mosquera. Ya la elección del género fantástico y su técnica metaléptica forman parte de esta estrategia de elogio de lo literario. Al hacer vacilar inexplicablemente el orden del mundo, el género fantástico permite desde luego tematizar los poderes imaginarios de la literatura, su capacidad de engendrar mundos paralelos, posibles o improbables. Pero en el caso peculiar del Manifiesto de Mosquera, se ha mostrado que tanto la oposición fantástica entre realidad e irrealidad como

\footnotetext{
8 "El lector es una fábula sin escribir" (22).
} 
la metalepsis se generan a partir de un hipotexto, La Celestina de Fernando de Rojas, obra clásica del panteón literario hispánico. Esta construcción refleja sin duda la práctica de lectura y de escritura que reivindicaba Marta Mosquera, junto con su amigo y coterráneo Borges. En una entrevista del 2010, declaraba la escritora: "yo no leo muchos contemporáneos, y él [Borges] tampoco leía muchos contemporáneos. Nosotros releíamos, creo mucho en la relectura" (Martínez Ubieda, 2010: s/p). Para la autora, cada lectura es una recreación y cada escritura es una reescritura de una literatura anterior que nos enriquece y que enriquecemos.

Esta concepción de la literatura como co-creación representa un verdadero leitmotiv del Manifiesto de Celestina: "Lo compagino nuevamente y me vuelvo a perder en sus páginas. Cada relectura crea nuevas aperturas y posibles secuencias" (115). Esta consideración de la lectura como acto de creación desemboca en la afirmación del poder de fascinación intrínseco de la literatura:

Presiento que en el texto hay en el fondo, otro texto. Es un texto oculto que trato de descubrir y no lo descubro. Pienso que en todo texto existen otros textos que no han sido escritos pero no están adormecidos para que alguien los descubra y los escriba, cuando presiente su existencia. Hay zonas de sombra en todo texto y esa oscuridad forma parte de un texto total que es el desencadenamiento de la literatura en sus mil versiones de la posible tradición de su magia. La literatura es parte de la magia. (64)

Las zonas de sombra a las que alude la narradora bien pueden referirse al sentido inagotable, y por tanto inabarcable en su totalidad, de la obra literaria. Cualquiera que sea nuestro esfuerzo para descodificar un texto, siempre permanecerá un fragmento de sentido huidizo, que hará necesarias otras relecturas y reescrituras en una cadena de creación infinita. Por eso no consigue la narradora ordenar el manuscrito. Sin embargo, en este afán obsesivo por entender el texto, el lector sufre la influencia de su objeto de estudio; el manuscrito se apodera de la narradora, la literatura se apodera de quien la lee: "La escritura de Celestina se me antoja mi escritura. Ya no escribo como yo escribía. Mis rasgos caligráficos se han modificado. [...] Trato de escapar del texto de Celestina" (52).

Las rupturas del cronotopo y de la voz narrativa que presenté con anterioridad pueden encontrar una explicación si aceptamos considerar el Manifiesto de Celestina como metáfora laudatoria de la literatura y de su funcionamiento. Por un lado, la dilución del marco cronológico permite generar en el relato una atemporalidad que bien podría aludir a la capacidad de vencer el tiempo que tienen las grandes obras literarias, como La Celestina. A este respecto, justamente afirma la periodista, al principio de su narración que "Celestina es la fábula escrita entre dientes en la realidad de la gritería de las grandes obras inmortales" (22). La pérdida de las referencias espaciales, por su parte, hace posible una espacialización de la literatura: "toda calle es un texto. Todo texto es una ciudad hecha con mil ciudades" (114). Estas metáforas espaciales de la textualidad constituyen otra manera de presentar la literatura como un palinsesto y un patrimonio colectivo.

Por otro lado, las interrogaciones existencialistas de la narradora y la problematización de su ser que se agudiza con su empeño en entender el manuscrito conforman un proceso que bien puede simbolizar la función principal de la literatura: hacernos reflexionar acerca de nuestra naturaleza y de nuestro lugar en el mundo.

Otra reflexión sobre la literatura que constituye un leitmotiv del Manifiesto de Celestina es la que atañe a la relación entre realidad y ficción. Como es obvio, este nexo viene ya problematizado por la pertenencia de nuestra novela corta al género fantástico. Además, la ruptura que lleva a cabo la narradora en relación con las referencias espacio-temporales y ontológicas que condicionaban su vida la conduce a afirmar la primacía de la ficción con respecto a la realidad: "Pienso en el «Manifiesto de Celestina» y creo que es una versión incompleta de la realidad. Todo manuscrito es real y todo libro es algo de la eternidad. El libro 
es un objeto errante; el lector es un sujeto errante. El nexo se llama: Literatura" (115); o, unas páginas después: "Pienso en el «Manifiesto de Celestina». Tal vez esas páginas como todo libro es un objeto mágico. Todo libro es inconcluso. La ficción es la realidad. La realidad es un libro mal escrito, un borrador incansable que no encuentra su punto final" (117).

También se supedita la historia a la ficción cuando la narradora - que en cierto momento de su relato observa el submundo de las alimañas que pueblan su vecindarioexplica:

Alguna alimaña dice que la historia es la ficción. Otras hablan de recuerdos futuros y aseguran que la historia no existe porque es inventada. Algunas alimañas ensayan corregir esas versiones y narran el pasado inventando otras versiones que contradicen a las anteriores y así van creando un eslabón que une errores y rectificaciones constantes. (77)

Esta (con)fusión heterodoxa entre historia y ficción evoca sin duda el postulado de la nueva novela histórica latinoamericana. Nacida en los años 80, dicha corriente considera el texto histórico como una construcción subjetiva, ya que nunca es posible alcanzar la verdad de los acontecimientos.

\section{Conclusiones}

Mediante tal problematización de la realidad llevada a cabo a partir de un documento, aquí el manuscrito celestinesco, el Manifiesto de Celestina nos puede recordar lo que González Echevarría (1998) llama la "ficción de archivo". En su ensayo Mito y archivo. Una teoría de la narrativa latinoamericana, el crítico interpreta toda la ficción latinoamericana como un discurso que dialoga, más o menos explícitamente, con un "archivo", o sea un discurso de autoridad. Este discurso de autoridad puede ser una crónica, una ley o, añado yo a partir del caso de Mosquera, una obra literaria canónica. La presencia de este diálogo da muestra de la insoslayable herencia cultural con respecto a la cual la literatura tiene que adaptarse. González Echevarría subraya además la frecuente caracterización de los personajes que encarnan el archivo como figuras ancianas cuya memoria es incierta:

La presencia de personajes viejos, moribundos o muertos en la ficción latinoamericana actual es notable y significativa. [...] Estas figuras oraculares son vínculos con el pasado y depósitos de conocimientos, como archivos vivientes. Pero sus recuerdos son incompletos y selectivos. La senilidad es una figura que representa los huecos en estos personajes de archivo. La senilidad, curiosamente, se transforma en fuerza para una creación exuberante, para la originalidad. [...] la senilidad es una metáfora de la cualidad incompleta del Archivo, pero también de la fuerza cohesiva, del pegamento con que se unen los textos. (1998: 249)

El crítico cita los ejemplos de Melquíades (en Cien años de soledad de Gabriel García Márquez) o de Colón (en El arpa y la sombra de Alejo Carpentier), antes de señalar otra peculiaridad de estos personajes: "Su edad también los acerca a la muerte, uno de los tropos fundadores de las ficciones de archivo. La muerte representa el hueco de huecos, el hueco maestro del Archivo, su clave inicial y final" (1998: 249). Aquí es necesario indicar que si el personaje de Celestina - tal y como se describe tanto en la obra de Rojas como en sus representaciones iconográficas $-{ }^{9}$ destaca por su vejez, es justamente en este rasgo físico de la alcahueta que insiste más la reescritura de Mosquera: la narradora apunta así varias veces que "en la lectura del manuscrito llama la atención la inquietud de Celestina frente a la vejez, la muerte y el amor" (28). La vejez es por tanto otro leitmotiv celestinesco que contamina el relato de la periodista, ya que entra en consonancia con el contexto de saqueo con el que se abre la

\footnotetext{
${ }^{9}$ Véanse por ejemplo los lienzos que a este personaje dedicaron Goya o Picasso.
} 
novela corta. La decrepitud, la miseria y la pérdida de la memoria que también acabarán asediando a la narradora, como intenté mostrar, por una parte reflejan la "huella del tiempo, del tiempo como cambio, como mutación" (1998: 251), y por otra parte justifican la imposible recopilación de un documento, aquí el manuscrito, necesariamente incompleto, como nuestro acceso al conocimiento del pasado.

En el Manifiesto de Celestina de Marta Mosquera, es, en fin, patente el desvío consciente de La Celestina, una obra mítica de la literatura española como afirmó Maeztu, hacia los nuevos desafíos de la literatura hispanoamericana del siglo XX. Vimos que el Manifiesto utiliza el hipotexto rojano para generar rupturas narrativas que a su vez posibilitan el enfrentamiento entre un orden racional del mundo y la irrupción de un acontecimiento que lo pone en tela de juicio. En otras palabras, la índole genérica fantástica de esta novela corta es el resultado de la introducción de La Celestina en un relato marco. Al utilizar de este modo un texto español canónico, La Celestina, para atacar las estructuras básicas de la narración, Marta Mosquera consigue además, y quizá paradójicamente, producir con el Manifiesto de Celestina un relato que no rompe con las tradiciones anteriores de la literatura hispanoamericana sino que las sintetiza. En efecto, combinando el cuento fantástico de Borges, la metalepsis de Cortázar o la nueva novela histórica, Mosquera firma un manifiesto estético cuyo presupuesto es, evidentemente, la reescritura como clave de la literatura.

\section{BIBLIOGRAFÍA PRIMARIA}

MOSQUERA, Marta (1995): Manifiesto de Celestina. Caracas, Miguel Ángel García.

ROJAS, Fernando de, y "antiguo autor" (2011): La Celestina. Tragicomedia de Calisto y Melibea. Edición y estudio de Francisco J. Lobera, Guillermo Serés, Paloma Díaz-Mas, Carlos Mota, Iñigo Ruiz Arzalluz y Francisco Rico. Barcelona, Galaxia GutenbergCírculo de Lectores, Colección "Biblioteca Clásica de la Real Academia Española".

\section{BIBLIOGRAFÍA SECUNDARIA}

ALMEIDA, Ivan (1999): "Borges, o los laberintos de la inmanencia", Borges: desesperaciones aparentes y consuelos secretos. Ed. Rafael Olea Franco. Ciudad de México, El Colegio de México, 35-59.

ANDRADE, Pilar, Gimber, Arno, y Goicoechea de Jorge, María, coords. (2010): Espacios y tiempos de lo fantástico. Una mirada desde el siglo XXI. Berna, Peter Lang.

BAJTÍN, Mijail M. (1989): "Las formas de tiempo y del cronotopo en la novela. Ensayos de poética histórica", Teoría y estética de la novela. Madrid, Taurus, 237-409.

BATAILLON, Marcel (1961): La Célestine selon Fernando de Rojas. París, Didier.

BEMONG, Nele, et alii, eds. (2010): Bakhtin's Theory of the Literary Chronotope: Reflections, Applications, Perspectives. Gante, Academia Press.

COHN, Dorrit, y Gleich, Lewis S.: "Metalepsis and Mise en Abyme", Narrative, XX/1 (2012), 105-114.

FLUDERNIK, Monika (2005): "Changement de scène et mode métaleptique", Métalepses. Entorses au pacte de la représentation. París, Éditions de l'École des Hautes Études en sciences sociales.

GENETTE, Gérard (2004): Métalepse: de la figure à la fiction. París, Seuil.

GONZÁLEZ ECHEVARRÍA, Roberto (1998): Mito y archivo. Una teoría de la narrativa latinoamericana. Ciudad de México, Fondo de Cultura Económica.

GONZÁLEZ SALVADOR, Ana: “Autour du concept de fantastique en littérature”, Anuario de estudios filológicos, 3 (1980), 77-88. 
— : "De lo fantástico y de la literatura fantástica", Anuario de estudios filológicos, 7 (1984), 207-226.

HEUGAS, Pierre (1973): La Célestine et sa descendance directe. Burdeos, Institut d'études ibériques et ibéro-américains.

LIDA DE MALKIEL, María Rosa (1961): La originalidad artística de La Celestina. Buenos Aires, Eudeba.

LÓPEZ PELLISA, Teresa, y Moreno Serrano, Fernando Ángel, eds. (2008): Ensayos sobre ciencia ficción y literatura fantástica. Madrid, Universidad Carlos III.

LUTAS, Liviu: "Dos ejemplos de metalepsis narrativas: Niebla de Miguel de Unamuno y Biblique des derniers gestes de Patrick Chamoiseau", Modern Sprach, 2 (2009), 39-59.

MAESTRO, Jesús G. (2001): El personaje nihilista. La Celestina y el teatro europeo. Madrid/Frankfurt, Iberoamericana/Vervuert.

MARTÍNEZ UBIEDA, Alejandro: "Marta Mosquera Eastman: la escritora". Prodavinci, http://prodavinci.com/2010/02/26/artes/testimonios-inmigrantes/marta-mosqueraeastman-la-escritora/, 26/02/2010.

(C) Jéromine François

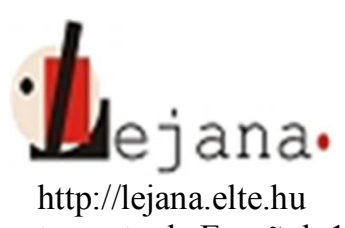

Universidad Eötvös Loránd, Departamento de Español, 1088 Budapest, Múzeum krt. 4/C

Recibido: 16 de febrero de 2015

Aceptado: 13 de octubre de 2015 